\section{Fibreoptic bronchoscopic intubation after induction of general anaesthesia: another approach}

To the Editor:

Oral or nasal intubation of the trachea under fibreoptic guidance is now recognised as the safest and most effective technique in known or suspected cases of difficult intubation. However, it is most successful in awake spontaneously breathing patients. Poor results can be expected when the technique is used as a last resort approach in an anaesthetized, paralysed patient in whom difficult intubation could not or was not predicted before induction of anaesthesia. ${ }^{1}$ In particular, the use of longacting non-depolarizing muscle relaxant drugs or megadoses of narcotics may create a situation that is not rapidly reversible.

We recently experienced such a problem. After induction of anaesthesia in a patient for CABG, with $5 \mathrm{mg}$ fentanyl, $5 \mathrm{mg}$ midazolam and $10 \mathrm{mg}$ vecuronium, it was impossible to visualize the vocal cords or intubate the patient after several attempts. Ventilation by mask was easy and the oxygen saturation remained $>98 \%$. After many attempts with a fibreoptic bronchoscope we were unable to visualize the vocal cords, because of oropharyngeal soft tissues and the presence of secretions and blood.

To solve that problem, we combined two techniques: a bronchoscope ( $6 \mathrm{~mm}$ diameter) was inserted through an 8 $\mathrm{mm}$ ID endotracheal tube until its tip was visible in the oropharynx. At that time, a second anaesthetist inserted a laryngoscope (McIntosh blade) in the usual manner in order to pull up the tongue, the epiglottis and soft tissues of the anterior larynx (Figure). The second anaesthetist was able to guide the first for his aim with the bronchoscope. It took less than a minute to intubate the trachea that way.

We think such a technique may be helpful to others when confronted with a similar problem.

\section{Pierre Couture MD}

Claude Perreault MD

Dominique Girard MD

Hôpital Notre Dame

Montréal

\section{REFERENCE}

1 Ovassapian, Yelich, Dykes, Brunner. Fiberoptic nasotracheal intubation. Incidence and causes of failure. Anesth Analg 1983; 62: 692-5.

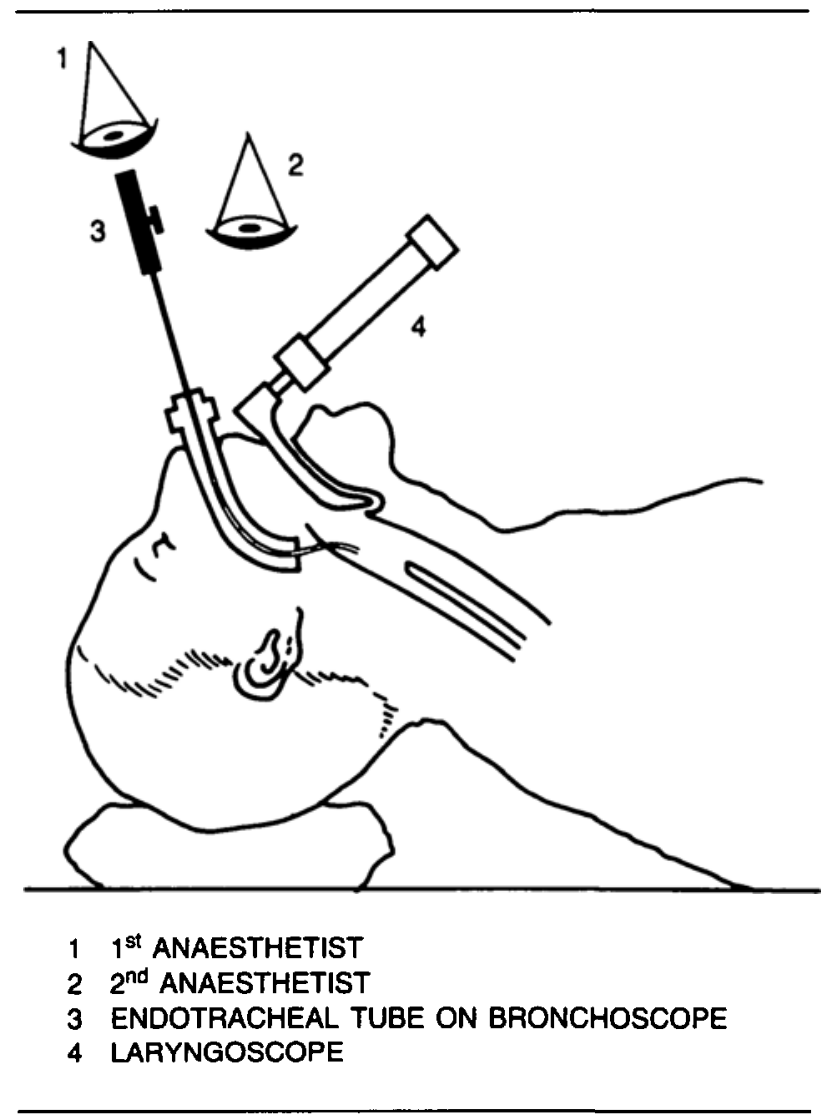

FIGURE

\section{Hyperthermia after cardio- pulmonary bypass in a child}

\section{To the Editor:}

Diagnosis of malignant hyperthermia (MH) during and after cardiopulmonary bypass (CPB) may be difficult secondary to the hypermetabolic state induced by extracorporeal circulation. We report a case of a three-year-old 10 $\mathrm{kg}$ female scheduled for elective repair of an atrial secundum defect. There was a history of postoperative fevers to $40^{\circ} \mathrm{C}$ after myringotomy tubes, and $38.5^{\circ} \mathrm{C}$ after strabismus surgery, and a maternal aunt had died perioperatively of "heat stroke." Because of her history a nontriggering anaesthetic was provided, and surgery was completed uneventfully.

Six hours after operation the patient was noted to have a base deficit of $6.2 \mathrm{mEq} \cdot \mathrm{L}^{-1}$ associated with an increasing temperature, respiratory rate, heart rate and $\mathrm{PaCO}_{2}$ with a constant minute ventilation. Central venous pressure was stable at 5-6 mmHg and urine output decreased from $5 \mathrm{ml} \cdot \mathrm{kg}^{-1} \cdot \mathrm{hr}^{-1}$ to less than $1 \mathrm{ml} \cdot \mathrm{kg}^{-1} \cdot \mathrm{hr}^{-1}$. Despite the 
concern for malignant hyperthermia, a diagnosis of relative hypovolaemia and hypoperfusion was made in the context of a hypermetabolic post-CPB state. A fluid bolus $\left(15 \mathrm{ml} \cdot \mathrm{kg}^{-1}\right)$ was administered and a dobutamine infusion $\left(5 \mu \mathrm{g} \cdot \mathrm{kg}^{-1} \cdot \mathrm{min}^{-1}\right)$ was initiated. The patient was sedated with morphine and additional muscle relaxant administered. The acidosis cleared rapidly, central venous pressure increased to $11 \mathrm{mmHg}$, heart rate decreased, and urine output increased. The patient recovered uneventfully. Attempts to persuade the family to undergo definitive MH diagnosis were unsuccessful.

The unphysiological state caused by CPB may produce conditions similar to a malignant hyperthermia episode in the postoperative period with rapid increases in temperature and carbon dioxide production. ${ }^{1,2}$ Allen and Cattran ${ }^{3}$ reported a hyperthermic episode in a MH susceptible patient after CPB treated with dantrolene. The patient developed a pneumonia attributed to pulmonary aspiration from the subsequent muscle weakness. Subsequent review by the authors determined that the episode was secondary to a hypermetabolic state after CPB. Awareness and close observation of postoperative metabolic changes after CPB combined with appropriate fluid management, sedation and ventilatory adjustments may prevent the unnecessary administration of dantrolene.

Paul D. Mongan MD

Michael P. Hosking MD

Anesthesia and Operative Service

Department of Surgery

Brooke Army Medical Center

Fort Sam Houston, Texas 78234-6200

(The opinions or assertions contained herein are the private views of the authors and are not to be construed as reflecting the view of the Department of the Army or the Department of Defense)

\section{REFERENCES}

1 Sladen $R N$. Temperature and ventilation after hypothermic cardiopulmonary bypass. Anesth Analg 1985; 64: 816-20.

2 Tulla H, Takala J, Alhava E, Huttunen H, Kari A. Hypermetabolism after coronary artery bypass. J Thorac Cardiovasc Surg 1991; 101: 598-600.

3 Allen GC, Cattran CB. Rewarming following hypothermic cardiopulmonary bypass in the malignant hyperthermia-susceptible patient: implications for diagnosis and management. Can J Anaesth 1989; 36: 81-5.

\section{Dual end-tidal $\mathrm{CO}_{2}$ monitoring and double-lumen tubes}

\section{To the Editor:}

We would like to report a technique that we have found to be useful in monitoring end-tidal $\mathrm{CO}_{2}\left(\mathrm{ETCO}_{2}\right)$ in the presence of a double-lumen tube.

Monitoring $\mathrm{ETCO}_{2}$ of each lung is a valuable adjunct to ensure proper double-lumen tube placement and also to detect its displacement during anaesthesia. Shafieha $e t$ al. ${ }^{1}$ used two end-tidal $\mathrm{CO}_{2}$ monitors to analyze $\mathrm{CO}_{2}$ wave forms from tracheal and bronchial lumens of the doublelumen tube, but using two monitors is not always practical or convenient. The following device uses a single capnometer.

Three 18-gauge needles cut at $2 \mathrm{~cm}$ are attached to the ports of a three-way stopcock. One short sampling tube is connected to one needle and two longer sampling tubes with tracheal adapters are connected to the other two ports of the stopcock. The short sampling tube is connected to the end-tidal port of the capnometer. The two tracheal adapters are connected to each lumen of the double-lumen tube via $8 \mathrm{~mm}$ portex endotracheal connectors as shown in the Figure. Using the three-way control of the stopcock, one can direct the sampling gas from tracheal, bronchial or both lumens. This enables the recording of $\mathrm{CO}_{2}$ wave forms from either of the lungs or from both lungs. Correct placement of the double-lumen tubes can be checked by analyzing the $\mathrm{CO}_{2}$ wave form from each lung and also during clamping and unclamping procedures of each lumen. Further, the $\mathrm{CO}_{2}$ wave forms can be examined periodically from each lung. A change in end-tidal concentration or $\mathrm{CO}_{2}$ wave form could give early warning of a misplaced double-lumen tube or inadequate ventilation and $\mathrm{CO}_{2}$ elimination from the lungs. We recommend that this method of $\mathrm{CO}_{2}$ analysis be used in addition to other conventional methods to increase the safety of doublelumen tubes.

\section{K.B. Shankar MD}

H.S.L. Moseley FFARCS

A.Y. Kumar MD

Department of Anaesthesia

Queen Elizabeth Hospital

University of West Indies, Barbados

\section{REFERENCE}

1 Shafieha MJ, Sit J, Kartha R et al. End-tidal $\mathrm{CO}_{2}$ analyzers in proper positioning of the double-lumen tubes. Anesthesiology 1986; 64: 844. 